NBER WORKING PAPER SERIES

\title{
INVESTOR SENTIMENT AND CORPORATE FINANCE: MICRO AND MACRO
}

\author{
Owen A. Lamont \\ Jeremy C. Stein \\ Working Paper 11882 \\ http://www.nber.org/papers/w11882
}

\author{
NATIONAL BUREAU OF ECONOMIC RESEARCH \\ 1050 Massachusetts Avenue \\ Cambridge, MA 02138 \\ December 2005
}

The views expressed herein are those of the author(s) and do not necessarily reflect the views of the National Bureau of Economic Research.

(C)2005 by Owen A. Lamont and Jeremy C. Stein. All rights reserved. Short sections of text, not to exceed two paragraphs, may be quoted without explicit permission provided that full credit, including $\odot$ notice, is given to the source. 
Investor Sentiment and Corporate Finance: Micro and Macro

Owen A. Lamont and Jeremy C. Stein

NBER Working Paper No. 11882

December 2005

JEL No. G14, G32, G34

\begin{abstract}
$\underline{\text { ABSTRACT }}$
We document that net equity issuance is considerably more sensitive to aggregate stock returns and Q's than to firm-level stock returns and Q's. Very similar patterns also emerge when we look at merger activity. In light of earlier work (Campbell 1991, Vuolteenaho 2002) which finds that aggregate stock returns are less informative about future cashflows than are firm-level stock returns-and thus, potentially more strongly influenced by investor sentiment--these results suggest that both equity issuance and mergers are to a significant extent driven by market-timing considerations, as opposed to by purely fundamental factors.
\end{abstract}

Owen A. Lamont

Yale School of Management

135 Prospect Street

P.O. Box 208200

New Haven, CT 06520-8200

and NBER

owen.lamont@yale.edu

Jeremy C. Stein

Department of Economics

Harvard University

Littauer 209

Cambridge, MA 02138

and NBER

jeremy_stein@harvard.edu 


\section{Investor Sentiment and Corporate Finance: Micro and Macro}

\section{Owen A. Lamont and Jeremy C. Stein*}

Figure 1 plots three time series over the interval 1927-2003: i) a measure of aggregate net equity issuance in the U.S.; ii) a measure of aggregate merger activity; and iii) the aggregate market-to-book ratio. ${ }^{1}$ As can be clearly seen, and as a number of observers have pointed out, both equity issuance and merger activity are strongly correlated with the level of the stock market, and with each other.

Broadly speaking, there are two classes of theories that might explain these patterns. According to the neoclassical view, the market is efficient, and all movements in stock prices rationally reflect changes either in expected future cashflows or in proper discount rates. Thus if prices are high, firms might want to issue more equity because the flexibility inherent in a less-leveraged capital structure is especially appealing when a large number of positive-NPV projects are available. And similarly, mergers might be more valuable in such periods, because it becomes all the more important to reallocate capital to the highest-value users (Boyan Jovanovic and Peter L. Rousseau, 2002).

By contrast, the behavioral view argues that managers time their equity issues to take advantage of stock prices that are sometimes too high relative to fundamentals (e.g., Jay R. Ritter and Tim Loughran, 1995, Malcolm Baker and Jeffrey Wurgler 2000). And similarly, some mergers - in particular, stock-for-stock mergers - are nothing more than a leading example of such opportunistic timing, since a stock-for-stock merger makes a convenient excuse for a large equity issue that might otherwise be hard to justify (Andrei Shleifer and Robert W. Vishny 2003). ${ }^{2}$

In this paper, we provide some new evidence that cuts in favor of the behavioral view. Our starting point is Paul A. Samuelson's dictum that market efficiency is a better 
description of the pricing of individual stocks in the cross section than of the pricing of the aggregate market. As quoted by Robert J. Shiller (2001, p. 243), Samuelson claims:

"Modern markets show considerable micro efficiency...I [hypothesize] considerable macro inefficiency, in the sense of long waves in the time series of aggregate indexes of security prices below and above various definitions of fundamental values."

Samuelson's dictum has been made concrete in empirical work by John Campbell (1991) and Tuomo Vuolteenaho (2002). Campbell shows that innovations to aggregate stock returns are largely transitory: less than half of the variance in returns is due to changes in expected cashflows, leading to predictable reversals in future returns. If one adopts a behavioral perspective and thinks of return predictability as being indicative of investor sentiment, this is consistent with Samuelson's idea that the aggregate market is quite inefficient, with a large fraction of its price variation being due to non-fundamental factors. In contrast, Vuolteenaho shows that innovations to idiosyncratic firm-level returns are largely permanent: most of the variation in returns is driven by cashflow news, with a smaller component due to time-varying expected returns. This suggests that firm-level relative prices are reasonably efficient, with a smaller role for sentiment.

The key insight that underlies our testing strategy is the following: if a given movement (say one percent) in aggregate stock prices contains a greater proportion of investor sentiment than the same-sized movement in firm-level prices, then according to the behavioral/timing view, equity issuance and mergers should respond more sensitively to aggregate price movements than to firm-specific price movements. In contrast, according to the neoclassical view all movements in stock prices are about some aspect of fundamentals (either cashflows or discount rates) and so there should be no differential sensitivity to the aggregate vs. firm-specific components of prices. ${ }^{3}$ 
Using different data sources and sample periods, we find evidence in favor of the behavioral view. Net equity issuance is considerably more sensitive to aggregate stock returns and $Q$ 's than to firm-level returns and $Q$ 's. Very similar patterns also emerge when we look at merger activity. These results suggest that both equity issuance and mergers are to a significant extent driven by market-timing considerations, as opposed to by purely fundamental factors.

In addition to equity issuance and mergers, we also look at the behavior of investment. Here the predictions of the behavioral view are less clear-cut. Intuitively, a manager whose stock is overvalued will certainly want to issue more shares, but whether the proceeds of the issue go into new physical capital - as opposed to simply being invested in T-bills - is less obvious, and depends on considerations of time horizons and financial constraints (Jeremy C. Stein 1996). Interestingly, our empirical results for investment are less clear-cut as well. Depending on the specification, investment appears to be either equally sensitive to aggregate and firm-specific stock prices (as in the neoclassical view) or somewhat more sensitive to the former (as in the behavioral view).

\section{Data}

Our sample consists of all common stocks on CRSP. From CRSP we obtain the number of shares outstanding for each firm, as well as stock returns and prices. From Compustat we obtain capital expenditures, net capital stock, and the book value of equity. For pre-Compustat values of book equity, we use data from Ken French's web page. We calculate $Q$ as the ratio of the market value of equity to the book value of equity, and $I / K$ as the ratio of capital expenditures to net property plant and equipment at the beginning of the year. Our $Q$ series starts in 1927, and our $I / K$ series starts in 1963 , when 
Compustat coverage becomes sufficiently complete. We also obtain information on mergers from the CRSP merger database, starting in 1973.

Our measure of net equity issuance — an aggregate dollar-weighted version of which is plotted in Figure 1-follows Kent Daniel and Sheridan Titman (2006), and goes back to 1927. For each firm, we define net issuance in year $t$ as simply the split-adjusted percentage change in shares outstanding from December of year $t-1$ to December of year t. This change can be either negative (reflecting, e.g., share repurchases) or positive (reflecting, e.g., exercises of executive stock options, seasoned equity offerings, or stockfinanced mergers). Note that our issuance measure only covers firms that already exist on CRSP, so it does not include initial public offerings and other new lists. We do not use new lists because we require lagged variables to run our regressions. As shown in Owen A. Lamont (2002), adding new lists would roughly double the dollar quantity of issuance.

We compute market returns using three-year compounded value-weighted returns for all common stocks on CRSP. To generate a market-wide measure of $Q$, we take the ratio of the sum of the market capitalization of all stocks (for whom book value is available) to the sum of the book value of all stocks - this is the market-to-book series shown in Figure 1. For our regressions, we discard all observations for which $Q$ is greater than 100 or less than 0.01 . We also discard observations on $I / K$ for financial firms (those with an SIC code starting with 6), or for firms with negative investment. Finally, in a further effort to control outliers, we exclude from all regressions any firm in the bottom quintile of market capitalization in a given year. For regressions involving book value or capital stock, we additionally exclude firms in the bottom quintile of those variables in a given year. We should emphasize that our results are generally more 
striking if we do not employ these outlier screens, since their primary effect is to increase the estimated coefficients on firm-specific returns and $Q$ 's.

\section{Results}

Table 1 displays our results. For each firm-level dependent variable (equity issuance, mergers, or $I / K$ ) we run: (i) a bivariate regression in which the two independent variables are the return on the aggregate market over the prior three years, $R 3 Y R_{t-1}$, and the idiosyncratic return on the firm's stock over the prior three years, $\left(r 3 y r_{t-1}-R 3 Y R_{t-1}\right)$; and (ii) a bivariate regression in which the two independent variables are the market-tobook ratio for the aggregate market at the start of the year, $Q_{t-1}$, and the idiosyncratic market-to-book ratio for the firm at the start of the year, $\left(q_{t-1}-Q_{t-1}\right)$. The coefficients from the first set of regressions appear in the first two columns of the table; the coefficients from the second set appear in the third and fourth columns.

Row 1 of the table considers our net issuance measure over the period 1927-2003. From the first two columns we see that issuance responds positively to both aggregate and idiosyncratic returns. However, the coefficient on the former, at 0.020 , is almost seven times the coefficient on the latter, at 0.003 . The difference between the two is also strongly statistically significant, with a p-value of 0.006 . In the regression that uses $Q$ 's instead of returns, we get a similar result: the coefficient on aggregate $Q$ is 0.018 , while that on idiosyncratic $Q$ is 0.003 , with the difference again being highly significant.

To understand the economic magnitude of the coefficients reported in Row 1, it is helpful to know that average firm-level issuance is about 0.06 (i.e., a firm increases its shares outstanding by six percent in a typical year), while aggregate $Q$ has an average of 1.5. Thus the coefficient of 0.018 on aggregate $Q$ means that when $Q$ is twice its 
historical value (as occurred around 1999), we can expect issuance for an individual firm to be about 45 percent above its historical average $(0.018 * 1.5 / .06=0.45)$.

Rows 2 and 3 consider all mergers and stock-for-stock mergers respectively, over the sample period 1973-2000. The dependent variable in these regressions is a dummy that equals one if the firm in question was an acquirer in a merger that was first announced in the given year. The results run closely parallel to those for issuance, and are essentially identical whether we look at the returns regressions or the $Q$ regressions: in either type of specification, the aggregate component of stock prices has an effect on merger activity that is approximately six to seven times as big as the idiosyncratic component, with the differences again being statistically significant in all cases.

The quantitative effect of aggregate stock prices on merger activity is large as well. The unconditional probability of a firm in our sample being an acquirer in any given year is on the order of 3.0 percent. When aggregate $Q$ is twice its historical average, our regression estimates imply that this probability goes up by about 1.8 percentage points, or by 60 percent of the unconditional value.

Finally, in Row 4, we look at our investment measure $I / K$. Here the results are less clear-cut. When we put returns on the right-hand side, $I / K$ shows the same qualitative pattern as equity issuance and mergers - it is significantly more sensitive to market returns than to idiosyncratic returns, with coefficients on the two variables of 0.085 and 0.043 respectively. However, when we put $Q$ on the right-hand side, the coefficients are almost identical, at 0.046 and 0.040 respectively.

Thus overall, the investment results do not yield a decisive rejection of the neoclassical view. At the same time, if one takes the perspective that predictability in 
aggregate stock returns is driven by investor sentiment (rather than by rational variation in discount rates), the investment results can equally well be interpreted as consistent with a version of the behavioral model in which managers have short horizons and simply seek to maximize current stock prices. As demonstrated by Stein (1996), in such a world short-horizon managers still follow the dictates of $Q$ theory, so the link between investment and stock prices is similar to that in a neoclassical setting.

The results do allow for a more conclusive rejection of an alternative version of the behavioral model, one in which managers have long horizons, and seek to maximize their perception of fundamental value. Stein (1996) shows that in this case, managers ignore sentiment-driven fluctuations in stock prices when making investment decisions. According to our logic, this should lead to smaller coefficients on aggregate returns and $Q$ 's than on their idiosyncratic counterparts, a prediction for which we find no evidence.

However one interprets the results for investment, the difference between these results and those for issuance and mergers is instructive. In particular, if one stipulates that the patterns for investment in the $Q$-based regressions are entirely reflective of the neoclassical view, then it would seem hard to argue that the corresponding patterns for issuance and mergers also are, since they look so fundamentally different. For example, one cannot easily write off our behavioral interpretation of the issuance and merger results simply by appealing to some form of mis-measurement in idiosyncratic $Q$ 's, since the investment results suggest that, using the same data, it is quite possible to get equally high estimates for the coefficients on idiosyncratic and aggregate $Q$.

We have tried many robustness tests, including: 1) using year fixed effects when estimating the idiosyncratic coefficients; 2) using concave transforms of the independent 
variables such as logged returns and $\log (Q)$; and 3) Winsorizing the idiosyncratic independent variables (returns and $Q$ 's) at their $5^{\text {th }}$ and $95^{\text {th }}$ percentile values. The latter two are particularly relevant if one worries that, e.g., issuance or mergers are inherently concave functions of $Q$. If so, one could obtain different coefficients on the aggregate and idiosyncratic components of $Q$ simply because the latter has more variance.

As it turns out, however, the results reported in Table 1 hold up well to these variations. In all cases we continue to find that, for both issuance and mergers, the aggregate coefficients on returns and $Q$ are significantly higher than the idiosyncratic ones. For investment the patterns are more mixed, much as in Table 1: in some cases the coefficient on the aggregate component of stock prices is significantly higher than the firm-specific component, but this is far from universally true.

\section{Conclusions}

Corporate equity issuance and merger activity are substantially more sensitive to aggregate stock prices than to firm-level prices. This basic pattern is hard to reconcile with the neoclassical model. However, in light of the relatively greater degree of predictability in aggregate returns, it is what one would expect based on a market-timing model of corporate financing behavior.

Our basic empirical strategy can be applied in a variety of other ways. Beyond our specific macro-vs.-micro approach, one can imagine other methods of identifying more and less sentiment-prone components of stock prices, based perhaps on news events or trading by different types of investors. We predict that future work will uncover a general tendency for corporate issuance to respond more strongly to those components of stock prices that are relatively sentiment-intensive. 


\section{References}

Baker, Malcolm and Wurgler, Jeffrey. "The Equity Share in New Issues and Aggregate Stock Returns.” Journal of Finance, October 2000, 55(5), pp. 2219-2257.

Campbell, John Y. “A Variance Decomposition for Stock Returns.” Economic Journal, March 1991, 101(405), pp. 157-179.

Daniel, Kent, and Titman, Sheridan. "Market Reactions to Tangible and Intangible Information.” Journal of Finance, 2006, forthcoming.

Jovanovic, Boyan and Rousseau, Peter L. "The Q-Theory of Mergers.” American Economic Review Papers and Proceedings, May 2002, 92(2), pp. 198-204.

Lamont, Owen A. "Evaluating Value Weighting: Corporate Events and Market Timing." Working paper, Yale University, 2002.

Loughran, Tim and Ritter, Jay R. “The New Issues Puzzle.” Journal of Finance, March 1995, $\underline{50}(1)$, pp. 23-51.

Shiller, Robert J. Irrational Exuberance. New York: Broadway Books, 2001.

Shleifer, Andrei and Vishny, Robert W. "Stock Market Driven Acquisitions.” Journal of Financial Economics, December 2003, 70(3), pp. 295-311.

Stein, Jeremy C. "Rational Capital Budgeting in an Irrational World." Journal of Business, October 1996, 69 (4), pp. 429-455.

Verter, Geoffrey. “Timing Merger Waves.” Working paper, Harvard University, 2003.

Vuolteenaho, Tuomo. “What Drives Firm-Level Stock Returns?” Journal of Finance, February 2002, 57(1), pp. 233-264. 
Table 1

Sensitivity of Equity Issuance, Mergers and Investment to Market-Wide and Firm-Specific Components of Stock Prices

Returns Regressions

\begin{tabular}{|l|l|l|l|l|l|l|}
\hline & Aggregate & Firm & & Aggregate & Firm & \\
\hline & $R 3 Y R_{t-1}$ & $r 3 y r_{t-1}-R 3 Y R_{t-1}$ & $\mathrm{p}$-val & $Q_{t-1}$ & $q_{t-1}-Q_{t-1}$ & $\mathrm{p}$-val \\
\hline Dependent variable: & & & & & & \\
\hline 1. Net Issuance, & 0.020 & 0.003 & 0.006 & 0.018 & 0.003 & 0.000 \\
\hline 1927-2003 & $(3.36)$ & $(4.75)$ & & $(7.03)$ & $(4.09)$ & \\
\hline & & & & & & \\
\hline 2. All Mergers, & 0.020 & 0.003 & 0.007 & 0.013 & 0.002 & 0.000 \\
\hline 1973-2000 & $(3.34)$ & $(4.52)$ & & $(5.74)$ & $(2.34)$ & \\
\hline & & & & & & \\
\hline 3. Equity Mergers, & 0.012 & 0.002 & 0.049 & 0.012 & 0.002 & 0.000 \\
\hline $1973-2000$ & $(2.43)$ & $(3.32)$ & & $(7.92)$ & $(3.81)$ & \\
\hline & & & & & & \\
\hline 4. I/K, & 0.085 & 0.043 & 0.001 & 0.046 & 0.040 & 0.586 \\
\hline $1963-2003$ & $(8.03)$ & $(14.32)$ & & $(3.55)$ & $(9.74)$ & \\
\hline & & & & & & \\
\hline
\end{tabular}

Note: For each firm-level dependent variable measured over year $t$ we run: (i) a bivariate regression in which the two independent variables are the return on the aggregate market over the three-year period ending in December of year $t-1, R 3 Y R_{t-1}$, and the idiosyncratic return on the firm's stock over the same period $\left(r 3 y r_{t-1}-R 3 Y R_{t-1}\right)$; and (ii) a bivariate regression in which the two independent variables are the market-to-book ratio for the aggregate market at the start of the year, $Q_{t-1}$, and the idiosyncratic market-tobook ratio, $\left(q_{t-1}-Q_{t-1}\right)$. The coefficients from the first set of regressions appear in the first two columns; those from the second set appear in the third and fourth columns. Net issuance is the change in the number of split-adjusted shares outstanding from year $t-1$ to year $t$, divided by shares outstanding in year $t-1$. Mergers are measured with a dummy that takes on the value one if the firm was the acquirer in a successful transaction that was announced in year $t$. $I / K$ is capital expenditures in year $t$ divided by start-of-year property, plant and equipment. The t-statistics in parentheses are based on standard errors clustered by year. The p-values are from the test that the aggregate and firm-specific coefficients are equal. 
Figure 1

Aggregate Market-to-Book, Mergers, and Equity Issuance, 1927-2003

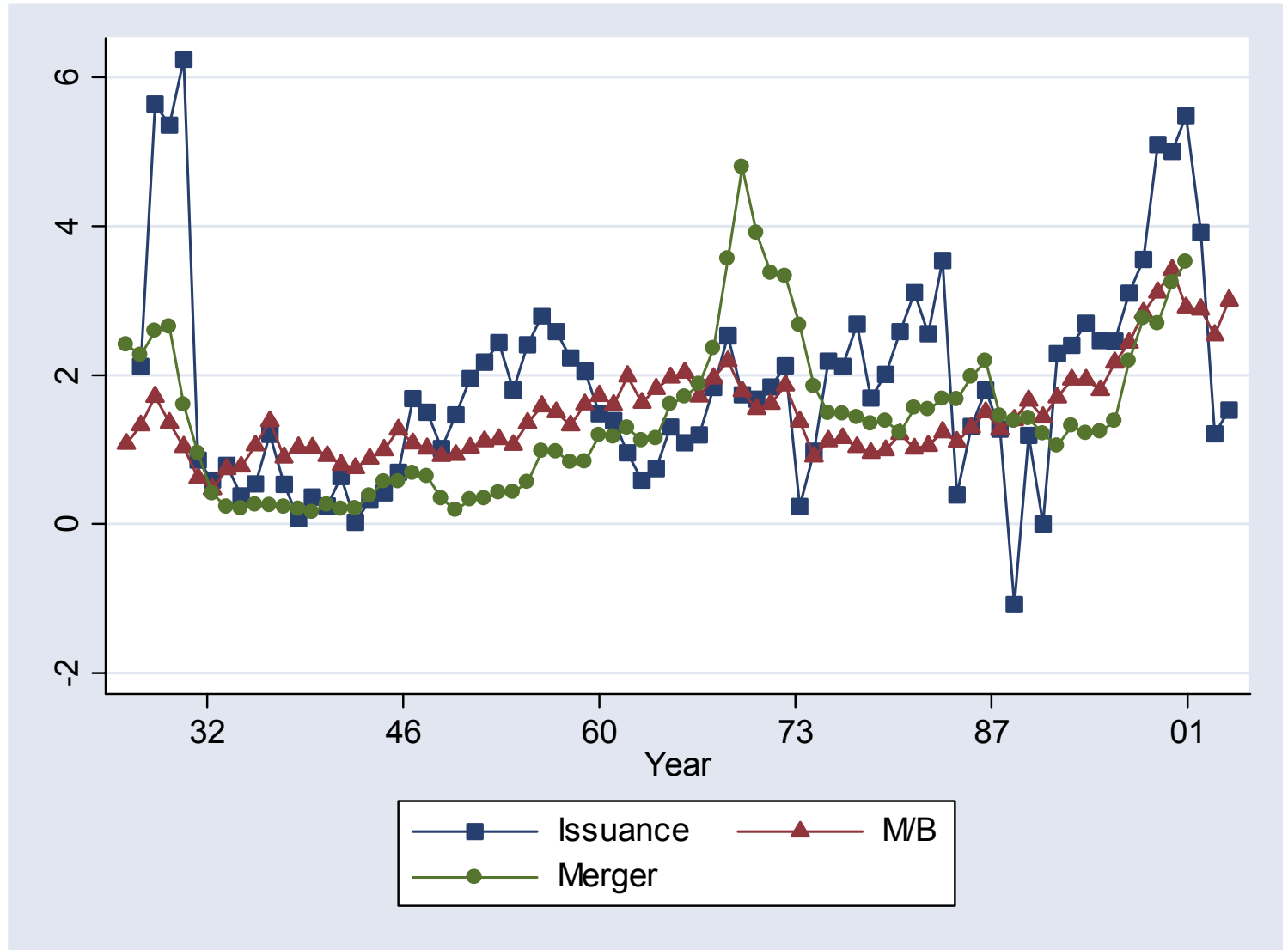

Note: Issuance is the dollar-weighted average of the annual change in individual firms' shares outstanding, expressed in percentage points. $\mathrm{M} / \mathrm{B}$ is the ratio of the aggregate market value of listed firms to their aggregate book value. Merger, which comes from Verter (2003), is the number of mergers in a given year divided by the number of listed firms. 


\section{Footnotes}

* Lamont: School of Management, Yale University, New Haven, CT 06520. Stein: Department of Economics, Harvard University, Cambridge, MA 02138. Thanks to the National Science Foundation for financial support, to Geoffrey Verter for sharing his merger data, to John Friedman for research assistance, and to Malcolm Baker and Tuomo Vuolteenaho for helpful comments.

${ }^{1}$ We describe the construction of the issuance and market-to-book variables below. The merger series is from Geoffrey Verter (2003) and is approximately the number of mergers in a given year divided by the number of publicly traded firms.

2 The most clear-cut prediction of the behavioral theory of mergers is that there will be more stock-for-stock mergers when the difference in the degree of overvaluation between acquirers and targets is large. To map this into a prediction involving the overall level of the market, one must implicitly assume that there is a pool of potential targets whose prices are relatively insensitive to investor sentiment, so that a wave of positive sentiment pushes up the prices of acquirers relative to these targets.

${ }^{3}$ A caveat is that, like the rest of the empirical $Q$ literature, we implicitly maintain the assumption of capital-stock homogeneity-i.e., there is no distinction between the value of assets in place and future investment opportunities. If this assumption fails to hold, one might observe, e.g., a higher sensitivity of equity issuance to the aggregate as opposed to firm-specific component of prices even in an efficient-markets setting, simply because the former is more informative about future investment opportunities, while the latter is more informative about the value of existing assets. 